\title{
An integer mathematical model for the problem of timetabling university exams
}

Elham Shadkam, Reza Rajabi

Department of Industrial Engineering, Faculty of Engineering, Khayyam University, Mashhad, Iran

\section{Keywords}

Timetabling problem,

Exams,

Modeling,

Integer programming.

\begin{abstract}
This research is an attempt to create optimized planning in educational units. The problem of university courses timetabling is one of the problems that is very important for educational units ;establishing optimal distances to comply with students' study status as well as balancing other constraints of the timetabling problem is one of the challenges in a timetabling problem. Therefore, sometimes an educational unit may not be able to strike a good balance between all the constraints it faces and fail to achieve a proper timing table. In this paper, in order to achieve optimal exam timetabling with an integer scheduling approach, a model for exam timetabling is presented. The purpose of the proposed mathematical model is to maximize the appropriate time intervals that should be established between students' exams. In this mathematical model, according to the number of allowed exam days and the number of possible exam sessions per day, a number of positions have been considered and it is tried to assign these positions to the courses according to the courses related to the students of each entrance. The most important advantage of the proposed model is its simplicity while sufficient accuracy. Therefore, complex methods are not needed to solve this model.
\end{abstract}

\section{Introduction}

Today, timetabling is one of the inevitable necessities of human life. In the macro programs of developed countries, one of the sectors that has played an important and effective role in achieving the realization of their programs and goals is the educational system. Therefore, considering the key role of the educational system in any society, it is possible to understand the importance of proper and appropriate planning in this system. Planners in the field of education in universities are always faced with various resources and limitations in setting the schedule of classes, so preparing a timeline taking into account all these limitations in a short time and without interfering with the expertise of resources as Non-automatic is very difficult. It is also not easy to make the necessary changes due to changes in the amount and timing of access to resources or changes in university policies regarding planning rules and priorities; On the other hand, with the quantitative expansion of colleges in terms of diversity of fields of study, student admission and degrees in Iran, the introduction of automatic methods of timetabling classes in a short period of time is necessary and inevitable [1].

The problem of university course schedule is one of the most important and widely used problems in educational environments. University course schedule is the allocation of a certain number of resources such as professors and courses to a limited number of time courses and classes in a given course according to It is a set of constraints to achieve a certain set of goals. In general, the purpose of creating a curriculum planning model is to reduce the interference of students in a department and teaching a professor, as well as to eliminate the synchronicity of courses that need a common class, so it can be said that a timetabling problem seeks to create a program with performability with minimal interference between courses. [2]

The problem of timetabling university courses in all cases belongs to the NP-hard class in terms of computational complexity; therefore, an algorithm with time complexity of polynomial order is not presented to solve it. Accurate algorithms and approximate algorithms can be used to solve timetabling problems [3] Genetic algorithms, forbidden search and cuckoo are among these algorithms. Despite the large number of models in the field of curriculum planning, not many studies have been done in the field of exam planning and, in this article,, a simple model for exam planning is presented. This model does not have the complexities of existing models and accurate approaches can be used to solve it. One of the approaches to modeling planning problems that is also considered in this article is integer programming and achieving the final model is based on the use of this approach; In the following sections of this mathematical model, the integer of the problem is examined and while presenting a model to satisfy the existing limitations, the test planning model is implemented in a case study and its results are examined in the following. This shows that despite the limitations that exist in educational units, it is possible to set up a program that can respond to existing limitations with optimization approaches.

\section{Literature and research background}

The timetable applies to a wide range of problems, including training problems, sports competitions, transportation problems, staff work schedules, meeting schedules, and production process timetabling. The timetable of educational problems is used in universities for timetabling courses, exams [4], deletions and additions [5] and in schools for timetabling courses, exams [6] and educators for teaching children with disabilities at home [7]. In the area of sports problems, the researchers used a timeline for scheduling basketball, football, table tennis, and baseball matches. The timetable is used in transportation problems to schedule the movement of buses [8], trains [9] and transits [10]. In the staff work schedule, a timetable is used for scheduling nurses [11] and aircraft crews [12]. In the production sector, a schedule has been used for human resource planning and management and production management, for example, the schedule of production processes in workshop production systems [13].

Research on machine scheduling dates back to the 1960s. In the early years, machine scheduling was a kind of simulation of manpower scheduling. The researchers then looked at more general methods, such as integer programming models. In the last two decades, efforts have focused on the use of innovative, metaphysical and artificial intelligence methods to solve such models. In 1963, Gilbert published numerous papers on mechanized scheduling in scientific conferences and journals. Also, many models in the form of mathematical models, computer models, graphs, etc. have been written in this field. The purpose of all these modeling is to provide a plan that is optimized to fit the goals, needs and resources of the organization by entering new
(1)

(E.shadkam Orcid: 0000-0003-3719-4665)

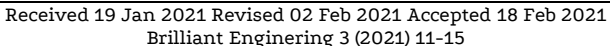

https://doi.org/10.36937/ben.2021.003.003 
information. In many articles, approaches such as ideal programs have been used to solve the timetabling problem. In these models, using ideal planning, attempts have been made to assign courses to professors in a way that meets the organization's needs and professors' preferences. In fact, ideal planning has tried to optimize the conflicting goals in the organization at the same time. In 1985 , Dora proposed various models and approaches with a special focus on graph theory [14]. In 2012, Saber et al. Used a bee meta-heuristic algorithm to solve the problem of exam timetabling and university course timetabling. The Bee Algorithm (HBMO) is a nature-inspired algorithm that simulates the actual mating process of bees [15]. In 2012, Abdullah and his colleague presented the problems of timetabling university courses and timetabling university exams, and solved the problems using the proposed forbidden mimetic algorithm with multiple neighborhood structure. Soft constraints Problems are designed based on students' preferences, and the goal of the problems is to minimize the number of violations of soft constraints. In the proposed algorithm, the mutation operator, the intersection, and 9 neighborhood structures and a forbidden list are used for the neighborhood structure. The results show that the desirability of the answers obtained from the proposed algorithm is only better than the memetic algorithm [16].

Alvarez-Valdez and colleagues in 2002 proposed a university course timetabling model and for the first time used the forbidden search algorithm to solve the university course timetabling problem. They solved the problem in two phases, the first phase is the allocation of students to courses and time periods and the second phase is the allocation of courses to classes. For the first phase, a possible initial answer for assigning students was generated and improved with the forbidden search algorithm of the program, and in the second phase, the forbidden search algorithm was used to allocate the class and improve it, without changing the initial allocation of courses to time periods. Also, several neighborhood strategies and the impact of structures have been compared [17]. In 1998, Badri introduced a model for optimizing the educational needs of the UAE University. In this model, limitations such as the amount of time available, the number of classes and the capacity of classes are considered. In addition, special attention has been paid to the faculty's policies, such as the number of classes held at night. In this model, teachers' preferences for lessons and time of each day are considered simultaneously. The structure of this model is in two stages. In the first stage, the lessons are assigned to the professors and in the second stage, the lessons are scheduled [18].

In 2006, Salem al-Yaqoub and Hanif Sharali developed models based on mathematical programming for the problem of assigning professors to courses at Kuwait University. The purpose of the integer mathematical programming model is to minimize individual and collective dissatisfaction of professors [19]. In 2012, Mehregan et al. Used the Soft System Methodology (SSM) method to solve the University of Tehran course timetabling problem. In this problem, the preferences of professors, students and the university have been considered. The purpose of the problem is to provide a quality timeline that minimizes violations of these preferences. Given the complexity and large size of examples of these problems in the real world, an efficient solution cannot be easily found. In this article, using SSM method, the concepts of learning, understanding and significant relationship of relevant stakeholders in the problem can be analyzed and examined [20]. In 1396, Shah Moradi and his colleagues had useful research in the field of timetabling university courses using the forbidden search algorithm and constraint planning in the field of timetabling university courses [3]. Ismaili and Abdollahi worked on two timetabling models in 2016 using the integer programming approach [1]. Abolfazl Rouhani also presented a study in the field of linear programming models of combined integer in the field of production planning, which is significant [21].

Reference [22] introduces some of the available methods to solve the scheduling problem, such as replacement method, graph coloring method, intelligent method, genetic algorithm, and the advantages and disadvantages of each of them are examined. Finally, it is concluded that using an integrated approach that considers the benefits of all methods will be the best approach to solve the problem. Various papers on scheduling problem at the university have been presented, which can be referred to as [23] and [24]

\section{The problem of exam timetabling and solution approaches}

In this section, first, explanations about educational planning models are presented, and then its solution approaches are briefly introduced, and finally, the planning of constraints and the concepts contained in it are stated.

\subsection{Exam timetabling problem}

Planning is a set of current preventive measures to solve the future problems of a system. According to this definition of planning, exam planning can be called a tactic in proper timetabling of exams of an educational group to solve problems and reduce dissatisfaction of users of educational systems. In this way, the future of the preplanning education system should be estimated and exam planning should be developed accordingly. The timeline tries to allocate a certain number of resources to a limited number of time and class periods in a given period according to a set of constraints, in order to achieve a certain set of goals.

\subsection{Problem solving approaches}

Approaches to solving optimization problems are different. According to one category, optimization problems are divided into two categories: hybrid and continuous optimization problems. In the context of continuous problems, many classical methods for global optimization have been proposed. But these techniques usually do not work if the objective function does not have certain properties, such as convexity. Continuous optimization methods are divided into two categories: linear and nonlinear optimization methods. Methods for solving hybrid optimization problems can also be divided into two parts: exact and approximate algorithms. Continuous nonlinear optimization and approximate methods of discrete problems are considered difficult problems.

\subsection{Integer programming}

Among the practical problems of optimization are those problems in which all or part of the variables are integers. These models have many applications in real-world problems because many variables in the real world are integers. When all decision variables are integers, this is called pure integer programming. If some variables have integer values (hence the assumption of divisibility for the rest), this model refers to Combined Integer (MIP) ${ }^{1}$ programming [21].

In recent years, integer programming models have received a lot of attention. With this approach, large size problems are solved directly and without decomposition into small size problems, and softness and flexibility in large size problems increases, and this problem is very important for the educational problems of universities or large institutions [25].

There are a limited number of papers on planning university exams, including [26], [27], [28], [29] and [30]. In these papers, more attention has been paid to the method of model solving and no new innovation has been presented regarding the modeling problem, while the main innovation of this paper is the presentation of a new model in this regard.

\section{The proposed integer model for exam planning}

In order to solve the future problems of an educational system, the future status of the educational system, including the lessons taken by students before planning, must be estimated and based on that, exam planning should be developed. Therefore, exam planning in this case can be divided into two parts:

\subsection{Predicting courses and number of students}

In most educational units, such as the case study of this research, the exams of all groups of a faculty are performed at the same time. Exams in each educational group include exams of general, basic, specialized courses and practical courses. To facilitate planning in most educational units, general and basic courses that are common to all groups are held at regular intervals and even the first or last days of exam days. Also, the exams for practical courses are not in the schedule and are held separately before or after the exams. Therefore, the most important part of planning in educational groups is the development of educational programs for specialized courses. 
The student grouping method can be used to estimate the group of courses that students take. In this method, the courses of an educational group are divided into 8 semesters (all the usual semesters of the undergraduate course) so that the priority and latency of taking courses are observed and the total number of units is divided approximately equally between 8 semesters. Also, the experiences of field counselors in taking courses in special semesters should be observed. These educational semesters are also referred to as "field trees". Students of each field are required to choose their courses in each semester based on the courses offered in the tree and corresponding to the number of semesters they have spent at the university. Therefore, by having the statistics of incoming students each year or current students of each semester, it is possible to select their courses in the next semester with a percentage of error (some students who fail to take some semester courses due to failure in a course) predicted.

\subsection{Determining the schedule of exams}

The second part of the exam timetabling problem is the allocation of exams to time intervals so that the existing restrictions are observed and the satisfaction of students in each category is met in the tree. At present, in most universities, the timetabling of courses is done manually by experienced people. In manual programming, lessons are scheduled in an iterative way. In each repetition, one course is selected and the schedule starts from two courses for which more students have registered for those two courses at the same time, so these two courses should not be offered at the same time and the date should be chosen. The test and the time interval should be done in a way that does not violate other restrictions. This process continues until all courses are assigned to the exam time frame. In the following, the assumptions and limitations of the proposed model of the article are examined:

1. It is assumed that there are a number of exam days and it is possible to assign a number of intervals to the exams each day, each of which is referred to as an exam post. With the help of this position, the exam time can be set every day.

2. The number and calendar of exam days and the number of exam time intervals (exam positions) per day are specified.

3. For each exam, only one time period (exam location) should be allocated from the schedule.

4. Exams in a semester of the tree should not be placed in a common exam location of the program. (Prevent student interference).

5. The limitation of the space available in each examination place for holding exams must be considered.

6. The interval between one semester exams in the tree should be maximized.

Variables and parameters of the proposed model

\section{Parameters:}

$\mathrm{N}$ : The number of exam seats available each day to hold exams $\mathrm{e}_{\mathrm{k}}$ : Number of semester exams

D: Number of days allowed for exams

Index:

$\mathrm{k}$ : Tree term number so that $1<\mathrm{k}<8$

i: Exam number in the $k$ semester so that $1<\mathrm{i}<\mathrm{e}_{\mathrm{k}}$

$\mathrm{t}$ : Number of exam positions per day $1<\mathrm{t}<\mathrm{N}$

j: Exam day number $1<\mathrm{j}<\mathrm{D}$

$\mathrm{D}_{(\mathrm{i}, \mathrm{ii}, \mathrm{k})}$ : Square Euclidean distance of exam time of two lessons

$\mathrm{i}$ and ii of the k semester

\section{Decision variable:}

$\mathrm{X}_{\mathrm{ijkt}}$ : is a variable of zero and one, and if the $\mathrm{i}$ exam of the $\mathrm{k}$ semester is held at $t$ hour of day $j$, the value is one, otherwise it is zero.

\section{Objective function of the proposed model}

The main innovation of the problem model is in its objective function. Thus, assuming $\mathrm{D}$ of the exam day and $\mathrm{N}$ position in each day, it is assumed that according to Table 1 , in total in the total interval of exams, the number of ND positions is available for assigning exams. Therefore, in the objective function of the problem, it is tried to assign the courses of each semester to these positions in such a way that the maximum time intervals between the positions are established. In fact, in the objective function of the problem, the distance between two courses $i$ and ii, which are in the same semester, is maximized, and in order to increase the distance between the two courses of each semester, the kt coefficient is used. In fact, the kt coefficient increases the distance between the two positions allocated for test $\mathrm{i}$ and $\mathrm{ii}$.

\begin{tabular}{|c|c|c|c|c|c|c|c|}
\hline \multicolumn{3}{|c|}{ The first day of exams } & $\ldots$. & \multicolumn{4}{|c|}{ The $D_{\text {th }}$ day of exams } \\
\hline $\begin{array}{c}\text { Position } \\
1 \\
\text { (First } \\
\text { hour) }\end{array}$ & $\begin{array}{c}\text { Position } \\
2 \\
\text { (Second } \\
\text { hour) }\end{array}$ & $\begin{array}{cc} & \text { Position } \\
& \mathrm{N} \\
\cdots & \left(\mathrm{N}_{\text {th }}\right. \\
& \text { hour })\end{array}$ & $\cdots$ & $\begin{array}{c}\text { Position } \\
\text { N(D-1) +1 } \\
\text { (First } \\
\text { hour) }\end{array}$ & $\begin{array}{c}\text { Position } \\
\mathrm{N}(\mathrm{D}-1)+2 \\
\text { (Second } \\
\text { hour) }\end{array}$ & & $\begin{array}{c}\text { Position } \\
\text { ND } \\
\text { ( } \mathrm{N}_{\text {th }} \\
\text { hour) }\end{array}$ \\
\hline
\end{tabular}

Table 1: Relationship between exam location and exam days

Due to the fact that the exams are held on D working days and at $\mathrm{N}$ different times of each day, so the exam program has ND positions and the kt coefficient causes the one-semester course exams to be located with the maximum distance between the positions. According to Equation 1 of the square Euclidean distance to calculate the time interval between exams.

$\operatorname{Max} D_{(\mathrm{i}, \mathrm{ii}, \mathrm{k})}=\sum_{\forall j=1, \ldots, k}\left(\sum_{i} \sum_{i i, i i \neq i}\left(\sum_{k} \sum_{t} K \cdot t \cdot X_{\mathrm{i}, \mathrm{i}, \mathrm{k}, \mathrm{t}}-\sum_{\boldsymbol{k}} \sum_{t} K \cdot t \cdot X_{\mathrm{ii}, \mathrm{j}, \mathrm{k}, \mathrm{t}}\right)^{2}\right)(1)$

Constraints of the proposed model:

1- Each lesson should be included in the exam program only once (Equation 2):

$\sum_{i} X_{i, j, k, t} \leq 1 ; \forall k=1, \ldots, 8 ; t=1, \ldots N ; j$

2-In each hour and each day (position) two lessons from one semester should not be allocated (Equation 3):

$\sum_{i} X_{i, j, k, t} \leq 1 ; \forall k=1, \ldots, 8 ; t=1, \ldots N ; j=1, \ldots, D$

3-Due to the limitation of the place of exams, a maximum of three lessons should be allocated per hour and each day (position) (Equation 4):

$$
\sum_{i} \sum_{j} X_{i, j, k, t} \leq 3 ; \forall k=1, \ldots, 8 ; t=1, \ldots N
$$

5. Implementing the proposed model for planning the courses of the Department of Industrial Engineering of Khayyam University

In this research, by collecting the required information related to the timetabling problem from the Department of Industrial Engineering of Khayyam University, the proposed model of the article was implemented and reviewed; the following is information about the model and the outputs of the model implementation.

\section{Evaluating the results of the proposed model}

Considering that in individual semesters (October semester) the emphasis of the Department of Industrial Engineering of Khayyam University is on the priority of planning based on individual semesters, so in this case studies due to time symmetry with individual semesters, planning based on individual semesters the person, which includes terms $1,3,5$ and 7 , is considered and the output of the model is of course based on the results of the person's terms. However, in the implementation of the proposed model, the courses related to even semesters have been considered, and for this purpose, these courses have been considered in one of the four courses of semesters $1,3,5$ and 7 , according to the position of the tree.

Khayyam University exams are held in 13 working days, except for the second and tenth days (which are for holding courses in the Department of Education). Also, each day of the exam includes three times of holding the exam as 8-10, 12: 30-10: 30 and 15-13. It is worth mentioning that in the semester, 29 specialized exams related to the industry group will be held. Tables 2 to 5 show the information about the courses along with the desired semester. 
Table 2: Lessons related to semester 1

\begin{tabular}{ccc}
\hline Lesson number & Term1=A & Name of Course \\
\hline 1 & $\mathrm{~A}_{1}$ & Economics 1 \\
2 & $\mathrm{~A}_{2}$ & Industrial Design and Drawing 1 \\
\hline
\end{tabular}

Table 3: Lessons related to semester $2 \& 3$

\begin{tabular}{ccc}
\hline $\begin{array}{c}\text { Lesson } \\
\text { number }\end{array}$ & $\begin{array}{c}\text { Term3 }=\mathbf{C} \\
\text { Term2=B }\end{array}$ & Name of Course \\
\hline 1 & $\mathrm{~B}_{1}$ & $\begin{array}{c}\text { Computer Programing } \\
\text { Statics and Strength of } \\
\text { Materials }\end{array}$ \\
2 & $\mathrm{~B}_{2}$ & $\begin{array}{c}\text { Theory of Statistics and } \\
\text { Probability } \\
3\end{array}$ \\
$\mathrm{C}_{1}$ & Material Science \\
4 & $\mathrm{C}_{2}$ & Fundamentals of Electric \\
5 & $\mathrm{C}_{3}$ & Engineering \\
6 & $\mathrm{C}_{4}$ & Linear Algebra \\
\hline
\end{tabular}

Table 4: Lessons related to semester $4 \& 5$

\begin{tabular}{ccc}
\hline $\begin{array}{c}\text { Lesson } \\
\text { number }\end{array}$ & $\begin{array}{c}\text { Term5=E } \\
\text { Term4=D }\end{array}$ & Name of Course \\
\hline 1 & $\mathrm{D}_{1}$ & Manufacturing Processes \\
2 & $\mathrm{D}_{2}$ & Engineering Economics \\
3 & $\mathrm{D}_{3}$ & Operation Research 1 \\
& $\mathrm{E}_{1}$ & Production Planning and \\
& Inventory Control 1 \\
4 & $\mathrm{E}_{2}$ & Project Management and \\
5 & $\mathrm{E}_{3}$ & Control \\
6 & $\mathrm{E}_{4}$ & Principles of Accounting \\
7 & $\mathrm{E}_{5}$ & Operation Research 2 \\
8 & & \\
\hline
\end{tabular}

Table 5: Lessons related to semester 6\&7\&8

\begin{tabular}{ccc}
\hline $\begin{array}{c}\text { Lesson } \\
\text { number }\end{array}$ & $\begin{array}{c}\text { Term6=F Term7= } \\
\text { Term8=H }\end{array}$ & Name of Course \\
\hline 1 & $\mathrm{G}_{1}$ & Principles of Marketing \\
2 & $\mathrm{G}_{2}$ & Facilities Planning \\
3 & $\mathrm{G}_{3}$ & System Dynamic \\
4 & $\mathrm{G}_{4}$ & Technical English \\
5 & $\mathrm{~F}_{1}$ & Quality Control \\
6 & $\mathrm{~F}_{2}$ & Simulation \\
7 & $\mathrm{~F}_{3}$ & Production Planning \\
8 & $\mathrm{~F}_{4}$ & Decision Analysis \\
9 & $\mathrm{~F}_{5}$ & Maintenance Planning \\
10 & $\mathrm{H}_{1}$ & Human Factors \\
11 & $\mathrm{H}_{2}$ & Engineering \\
12 & $\mathrm{H}_{3}$ & Design Of Industries \\
& & Management \\
13 & $\mathrm{H}_{4}$ & Information System \\
& & Inventory Planning And \\
\end{tabular}

Table 6: Exam program resulting from the implementation of the proposed model based on individual semester planning

\begin{tabular}{|c|c|c|c|c|c|}
\hline \multirow{2}{*}{$\frac{\text { Day }}{1}$} & 8-10 p.m. & \multicolumn{2}{|c|}{ 10:30-12:30 p.m. } & \multicolumn{2}{|c|}{ 13-15 a.m. } \\
\hline \multirow{2}{*}{\multicolumn{6}{|c|}{2}} \\
\hline & & & & & \\
\hline \multicolumn{6}{|l|}{3} \\
\hline 4 & $\mathrm{D}_{2}$ & & & \multicolumn{2}{|c|}{$E_{5}$} \\
\hline 5 & $\mathrm{C}_{2}$ & \multicolumn{2}{|c|}{$\mathrm{F}_{4}$} & $E_{3}$ & $\mathrm{~A}_{2}$ \\
\hline 6 & $\mathrm{G}_{4}$ & \multicolumn{2}{|c|}{$\mathrm{B}_{2}$} & \multicolumn{2}{|c|}{$\mathrm{G}_{2}$} \\
\hline 7 & & $\mathrm{~F}_{2}$ & $\mathrm{C}_{4}$ & \multicolumn{2}{|c|}{$\mathrm{H}_{1}$} \\
\hline 8 & & $\mathrm{H}_{3}$ & $E_{1}$ & \multicolumn{2}{|c|}{$\mathrm{H}_{4}$} \\
\hline 9 & $\mathrm{D}_{1}$ & & & \multicolumn{2}{|c|}{$F_{1}$} \\
\hline \multicolumn{6}{|l|}{10} \\
\hline 11 & $\mathrm{C}_{1}$ & $D_{3}$ & $\mathrm{~B}_{1}$ & $\mathrm{G}_{3}$ & $\mathrm{C}_{3}$ \\
\hline 12 & & \multicolumn{2}{|c|}{$\mathrm{E}_{2}$} & $\mathrm{~F}_{5}$ & $\mathrm{~A}_{1}$ \\
\hline 13 & & \multicolumn{2}{|c|}{$\mathrm{F}_{3}$} & $\mathrm{H}_{2}$ & $\mathrm{E}_{4}$ \\
\hline
\end{tabular}

The test program resulting from the implementation of the proposed model is shown in Table 6. As can be seen, due to the fact that the focus of planning is based on individual semester courses 1, 3, 5 and 7 , these courses are properly planned and allocated in 13 days with the maximum time interval.

\section{Conclusions and suggestions}

Research shows that the timetable applies to a wide range of problems, including training problems, sports competitions, transportation problems, staff work schedules, meeting schedules, and production process timetabling. The timetable can be used to schedule educational problems in universities for timetabling, exams, and additions, and in schools for timetabling lessons, exams, and instructors to teach children with disabilities at home.

This paper examines the models and methods of curriculum planning that are part of the complex optimization problems. One of the most important and challenging problems in this field is the problem of planning university exams. In this article, a model was presented in this field, which is a relatively simple yet practical model with sufficient accuracy. The main innovation of the proposed model is the problem objective function, which maximizes students' exam intervals, and the main purpose of the method is to provide sufficient time for students to study for exams.

The proposed model was used to plan the exams of the Department of Industrial Engineering of Khayyam University and the result was an exam program with the ability to be implemented in the university. For future research, the proposed model can be generalized and applied to other timetabling problems.

Also, other objective functions can be added to the problem, such as minimizing the number of exams in a given interval and considered the problem as multi-objective.

\section{Declaration of Conflict of Interests}

The authors declare that there is no conflict of interest. They have no known competing financial interests or personal relationships that could have appeared to influence the work reported in this paper.

\section{References}

[1.] Fügenschuh, A., Solving a school bus scheduling problem with integer programming. European Journal of Operational Research 193, no. 3 (2009) 867-884.

[2.] Stubbs, S., Inclusive education. Where there are few resources. Oslo, The Atlas Alliance Publ (2008).

[3.] Kelley, Jr., James, E., Critical-path planning and scheduling: Mathematical basis. Operations research 9, no. 3 (1961) 296-320.

[4.] Dimopoulou, M., Panagiotis, M., Implementation of a university course and examination timetabling system. European Journal of Operational Research 130, no. 1 (2001) 202-213.

[5.] Mehregan, M.R., Hosseinzadeh, M., Kazemi, A., An application of soft system methodology. Procedia-Social and Behavioral

[6.] Gunawan, A., Kien, M., Kim, L.P., A hybridized Lagrangian relaxation and simulated annealing method for the course timetabling problem. Computers \& Operations Research 39, no. 12 (2012) 3074-3088.

[7.] Head, Ch., Sami Sh., A heuristic approach to simultaneous course/student timetabling. Computers \& Operations Research 34, no. 4 (2007) 919-933.

[8.] Bartsch, Th., Andreas D., Stefan K., Scheduling the professional soccer leagues of Austria and Germany. Computers \& Operations Research 33, no. 7 (2006) 1907-1937.

[9.] Schönberger, J., Dirk C.M., Hubert K., Memetic algorithm timetabling for non-commercial sport leagues. European Journal of Operational Research 153, no. 1 (2004) 102-116.

[10.] Hoshino, R., Ken-ichi K., A multi-round generalization of the traveling tournament problem and its application to Japanese baseball. European journal of operational research 215, no. 2 (2011) 481-497.

[11.] Azaiez, M., Naceur, S., Shaza, Al.Sh., A 0-1 goal programming model for nurse scheduling." Computers \& Operations Research 32 , no. 3 (2005) 491-507. 
[12.] Weide, O., David R., Matthias E., An iterative approach to robust and integrated aircraft routing and crew scheduling. Computers \& Operations Research 37, no. 5 (2010) 833-844.

[13.] Basir, S.A., Mazdeh, M.M., Namakshenas, M., Bi-level genetic algorithms for a two-stage assembly flow-shop scheduling problem with batch delivery system. Computers \& Industrial Engineering 126 (2018) 217-231.

[14.] de Werra, D., An introduction to timetabling. European journal of operational research 19, no. 2 (1985) 151-162.

[15.] Sabar, A.A., Diagnostic study of FMD virus in different area in Iraq. The Iraqi Journal of Veterinary Medicine 36, no. OE (2012) 49-55.

[16.] Abdullah, S., Edmund K.B, Barry M., An investigation of variable neighbourhood search for university course timetabling. In The 2nd multidisciplinary international conference on scheduling: theory and applications (MISTA), (2005) 413-427.

[17.] Alvarez-Valdés, R., Francisco P., José M.T., A tabu search algorithm for assigning teachers to courses. Top 10, no. 2 (2002) 239-259.

[18.] Badri, M.A., Donald, L.D., Donna, F.D., John H., A multi-objective course scheduling model: Combining faculty preferences for courses and times. Computers \& operations research 25, no. 4 (1998) 303-316

[19.] Al-Yakoob, S.M., Hanif, D.Sh., A mixed-integer programming approach to a class timetabling problem: A case study with gender policies and traffic considerations. European Journal of Operational Research 180, no. 3 (2007) 1028-1044.

[20.] Mehregan, M.R., HosseinzadehM, Kazemi, A., An application of soft system methodology. Procedia-Social and Behavioral Sciences 41 (2012) 426-433.

[21.] Zhang, H., Vijay, V., Gerald, Th.H., Jaime Q., A mixed-integer linear programming approach for multi-stage securityconstrained transmission expansion planning."IEEE Transactions on Power Systems 27, no. 2 (2011) 1125-1133.

[22.] Diveev, A.I., Bobr, O.V., Kazaryan, D.E., Hussein, O., Some methods of solving the NP-difficult problem of optimal schedule for the university. Procedia Computer Science 150 (2019) 410-415.

[23.] Hossain, Sk.I., Akhand, M. A. H., Shuvo, M.I.R. , Nazmul S., Adeli H., Optimization of university course scheduling problem using particle swarm optimization with selective search. Expert Systems with Applications 127 (2019) 9-24.

[24.] Shiau, D., A hybrid particle swarm optimization for a university course scheduling problem with flexible preferences. Expert Systems with Applications 38, no. 1 (2011) 235-248.

[25.] Phillips, A.E., Hamish W., Matthias E., David M.R. Integer programming methods for large-scale practical classroom assignment problems. Computers \& Operations Research 53 (2015) 42-53.

[26.] Arani, T., Mark K., Lofti, V., A Lagrangian relaxation approach to solve the second phase of the exam scheduling problem. European Journal of Operational Research 34, no. 3 (1988) 372 383.

[27.] Sagir, M., Kamisli Ozturk, Z.,. Exam scheduling: Mathematical modeling and parameter estimation with the Analytic Network Process approach. Mathematical and Computer Modelling 52, no. 5-6 (2010) 930-941.

[28.] Abou Kasm, O., Mohandes, B., Diabat, A., and El Khatib, S., Exam timetabling with allowable conflicts within a time window." Computers \& Industrial Engineering 127 (2019) 263-273.

[29.] Goldsberry, J.W., Handwerker, S.M., Leslie C. Moore, L.C., BSN Exam Scheduling across Same Semester Courses-Improving Student Success: A Retrospective, Comparative, Descriptive Research Study. Teaching and Learning in Nursing 14, no. 1 (2019): 21-25.

[30.] Margot, V., A portfolio replacement for a traditional final exam in thermodynamics. Education for Chemical Engineers 35 (2021) 1-6.

\section{How to Cite This Article}

Shadkam, E., Rajabi, R., An integer mathematical model for the problem of timetabling university exams, Brilliant Engineering, 3(2021), 11-15. https://doi.org/10.36937/ben.2021.003.003 